\title{
A NEW APPROACH ON THE RESPONSE OF NON-UNIFORM PRESTRESSED TIMOSHENKO BEAMS ON ELASTIC FOUNDATION SUBJECTED TO HARMONIC LOADS
}

\author{
O.K. Ogunbamike \\ Department of Mathematical Sciences, Olusegun Agagu University of Science and \\ Technology, Okitipupa, Nigeria.
}

Corresponding author: ogunbamike2005@gmail.com (+2348036882101)

\section{Cite this article:}

O.K. Ogunbamike (2021), A New Approach on the Response of Non-Uniform Prestressed Timoshenko Beams on Elastic Foundation Subjected to Harmonic Loads. African Journal of Mathematics and Statistics Studies 4(2), 66-87. DOI: 10.52589/AJMSSNZXSUM3I.

\section{Manuscript History}

Received: 13 June 2021

Accepted: 9 July 2021

Published: 26 July 2021

Copyright $\odot 2020$ The Author(s). This is an Open Access article distributed under the terms of Creative Commons AttributionNonCommercial-NoDerivatives 4.0 International (CC BY-NC-ND 4.0 ), which permits anyone to share, use, reproduce and redistribute in any medium, provided the original author and source are credited.
ABSTRACT: The dynamic response of the Timoshenko beam resting on an elastic foundation subjected to harmonic moving load using modal analysis (MA) was investigated. The method of MA was employed to obtain a closed form solution to this class of dynamical systems. In order to use MA, accurate information is needed on the natural frequencies, mode shapes and orthogonality of the mode shapes. A thorough literature survey reveals that the method has not been reported in existing literature to solve non-prestressed Timoshenko beams. Thus, we present complete information on how to use MA to derive the forced vibration responses of a simply thick beam subjected to harmonic moving loads. The effects of axial force and foundation parameters on the dynamic characteristics of the beams are studied and described in detail. In order to validate the accuracy of this method, we compare the frequency parameter with the existing literature which appears to compare favorably.

KEYWORDS: Elastic Foundation; Harmonic Moving Load; Modal Analysis; Non-Prestressed; Timoshenko Beam. 


\section{INTRODUCTION}

The dynamic analysis of elastic structures on an elastic foundation is a major research field in the realms of structural Engineering, Physics and Applied Mathematics [1-7]. So far and during these years, many researchers have conducted different studies in this field. When moving loads are applied to a structure, dynamic deflections and stresses may become considerably higher than those induced by static loads. When structural members are under the passage of moving loads, the interaction between the passing load and the structure makes the dynamic response analysis very complex [1]. The work of Timoshenko [8] gave impetus to research work in this area of study. The analysis of the dynamic response of a simple beam continuously supported by a viscoelastic foundation to a moving load moving at variable speed was considered. The analysis reveals several resonance conditions depending on the visco-elasticity of the foundation. Also, a theory for the response to an arbitrary number of concentrated moving masses of a rectangular plate continually supported by an elastic Pasternak type foundation was developed [9]. It was found that the critical speeds of the system increased with an increase in the values of the foundation moduli, whether the inertia effect of the system is considered or not. By virtue of the relevance in the analysis and design of railway tracks, bridges, elevated roadways, decking slabs, etc., the dynamic response of structural members under the passage of moving loads have been extensively investigated and a number of experimental and numerical studies have been reported in literature in recent years [2-7]. In this study, the concern is beam-type flexure under harmonic moving loads. Many researchers have developed various solution techniques to the transverse vibration of Timoshenko beam, which include semi-analytical method [10-12], transform matrix method [13, 14], integral transform method [15, 16], Galerkin's methods [17], finite element method [18], finite difference method [19], frequency-domain spectral method [20], and time-domain spectral element method [21]. The analytical closed-form solution for a moving load problem using MA can be obtained when the information regarding natural frequencies, mode shapes and orthogonality properties of the mode shapes are derived. Many researchers have developed general solutions of the transverse vibrations of a Timoshenko beam. This include Han et al.

[22], the general solution is obtained for two frequencies ranges, $\omega<\omega_{c}$ and $\omega>\omega_{c}$, excluding the cutoff frequency $\omega_{c}$. Taehyum Kim et al. [23] and van Rensburg and van der Merwe [24] developed a general solution that includes the three frequencies ranges i.e $\omega \leq \omega_{c}$ and $\omega \geq \omega_{c}$ including the cutoff frequency $\omega_{c}$.

However, their method of solution cannot handle the variable prestressed Timoshenko beam. Thus, in this study, the discussion based on the mathematical formulation of the general solutions of prestressed variable simply supported Timoshenko beam, resting on an elastic foundation subjected to harmonic moving loads considering the frequency $\omega \leq \omega_{c}$ using MA.

\section{Problem Formulation}

The problem of prestressed Timoshenko beam of length $L$ on a bi-parametric foundation subjected to moving loads is governed by an initial boundary value system of equations. This system of equation can be written in matrix form as

$$
\mathbf{M} \frac{\partial^{2} v(x, t)}{\partial t^{2}}+\mathbf{K} v(x, t)=\mathbf{Q}(x, t)
$$


where

$$
\begin{gathered}
v(x, t)=\left\{\begin{array}{l}
u(x, t) \\
\phi(x, t)
\end{array}\right\} ; \mathbf{Q}(x, t)=\left\{\begin{array}{c}
f(x, t) \\
0
\end{array}\right\} \\
\mathbf{M}=\left[\begin{array}{ll}
1 & 0 \\
0 & 1
\end{array}\right] ; \mathbf{K}=\left[\begin{array}{cc}
K_{1}-\left(\eta_{1}+K_{N}(x)\right) \frac{\partial^{2}}{\partial x^{2}} & \eta_{1} \frac{\partial}{\partial x} \\
-\eta_{2} \frac{\partial}{\partial x} & \eta_{2}-r_{0} \frac{\partial^{2}}{\partial x^{2}}
\end{array}\right] \\
\eta_{1}=\frac{\varphi G}{\rho} ; \eta_{2}=\frac{\varphi G A}{\rho I} ; K_{1}=\frac{K_{\omega}}{\rho A} ; K_{N}(x)=\frac{N(x)}{\rho A} ; f(x, t)=\frac{F(x, t)}{\rho A} ; r_{0}=\frac{E}{\rho}
\end{gathered}
$$

$u(x, t)$ is the transverse displacement, $\phi(x, t)$ is the rotation of the cross section due to bending, $f(x, t)$ is the external transverse force, $N(x)=N_{0}\left(1+\sin \frac{\pi x}{L}\right)$ is the variable axial force, $N_{0}$ is the axial force at $x=0, K_{\omega}$ is the Winkler foundation, $E$ is the young modulus, $G$ is the shear modulus, $\rho$ is the mass density, $A$ is the cross-sectional area, $I$ is the moment of inertia and $\varphi$ is the shear correction factor. The natural and geometric boundary conditions relevant to Equation (1) are given by

$$
\begin{array}{llllll}
C(0, t)=-C_{1}(t) & \text { or } & u(0, t)=u_{1}(t) ; & C(L, t)=-C_{2}(t) & \text { or } & u(L, t)=u_{2}(t) ; \\
M(0, t)=C_{1}(t) & \text { or } & \phi(0, t)=\phi_{1}(t) ; & M(L, t)=M_{2}(t) & \text { or } & \phi(L, t)=\phi_{2}(t) ;
\end{array}
$$

where $C(x, t)$ and $M(x, t)$ are the transverse shear force and bending moment respectively, given as

$$
C(x, t)=\varphi G A\left(\frac{\partial u}{\partial x}-\phi\right) ; M(x, t)=E I \frac{\partial \phi}{\partial x}
$$

and the initial conditions are given as

$$
\mathbf{v}(x, 0)=\mathbf{g}(x) ; \frac{\partial \mathbf{v}(x, 0)}{\partial t}=\mathbf{h}(x)
$$

\section{THE FREE AND FORCED VIBRATION}

\section{General Solution}

In order to obtain the eigenfunctions (natural modes) for the model under discussion, the general solutions for the free vibration with constant axial force must first be obtained. Thus, we considered the homogeneous equation of Equation (1) when the axial force is constant as follows:

$$
\mathbf{M} \frac{\partial^{2} v(x, t)}{\partial t^{2}}+\mathbf{K} v(x, t)=0
$$


We assume the solution of Equation (6) is in the following form:

$$
\begin{array}{r}
v(x, t)=\left\{\begin{array}{l}
U(x) \\
\Phi(x)
\end{array}\right\} e^{i \omega t}=\mathbf{V}(x) e^{i \omega t} \\
\text { where } \mathbf{V}(x)=\mathbf{d} e^{r x}
\end{array}
$$

where $i$ is an imaginary number, $\omega$ is the angular frequency and $r$ denotes the wave number. Therefore, substituting Equation (7) into Equation (6) yields the following algebraic equations:

$$
\left[\begin{array}{cc}
-\beta_{1} r^{2}+\beta_{3} & r \eta_{1} \\
r \eta_{2} & -r_{0} r^{2}+\beta_{2}
\end{array}\right] \mathbf{d} e^{r x}=\left\{\begin{array}{l}
0 \\
0
\end{array}\right\}
$$

where

$$
\beta_{1}=\left(\eta_{1}+K_{N}\right) ; \beta_{2}=\eta_{2}-\omega^{2} ; \beta_{3}=K_{1}-\omega^{2} ; K_{N}=\frac{N_{0}}{\rho A}
$$

from which we obtain eigenvalues $r$. For the existence of non-trivial solutions, the determinant of the $2 \times 2$ matrix in Equation (8) must vanish at certain values of $r$. Thus, a dispersion equation is obtained as follows:

$$
r^{4}-\frac{1}{r_{0} \beta_{1}}\left(\beta_{1} \beta_{2}+r_{0} \beta_{3}-\eta_{1} \eta_{2}\right) r^{2}+\frac{\beta_{2} \beta_{3}}{r_{0} \beta_{1}}=0
$$

The eigenvalues are given by

$$
\begin{array}{r}
r_{i}= \pm \sqrt{\frac{1}{2 r_{0} \beta_{1}}\left[\left(\beta_{1} \beta_{2}+r_{0} \beta_{3}-\eta_{1} \eta_{2}\right) \pm \sqrt{\left(\beta_{1} \beta_{2}+r_{0} \beta_{3}-\eta_{1} \eta_{2}\right)^{2}-4 r_{0} \beta_{1} \beta_{2} \beta_{3}}\right]} \\
\text { for } i=1,2,3,4
\end{array}
$$

The corresponding eigenvectors $\mathbf{v}_{\mathbf{i}}$ are given by

$$
\mathbf{v}_{\mathbf{i}}=\left[\begin{array}{c}
r \eta_{1} \\
-\beta_{1} r^{2}+\beta_{3}
\end{array}\right] \text { or }\left[\begin{array}{c}
-r_{0} r^{2}+\beta_{2} \\
r \eta_{1}
\end{array}\right]
$$

Of the four roots, the two given by

$$
r_{j}= \pm \sqrt{\frac{1}{2 r_{0} \beta_{1}}\left[\left(\beta_{1} \beta_{2}+r_{0} \beta_{3}-\eta_{1} \eta_{2}\right) \pm \sqrt{\left(\beta_{1} \beta_{2}+r_{0} \beta_{3}-\eta_{1} \eta_{2}\right)^{2}-4 r_{0} \beta_{1} \beta_{2} \beta_{3}}\right]}
$$

$$
\text { for } j=1,2
$$


are either real or imaginary depending on the frequency $\omega$ (for a given material and geometry), and the other two roots given by

$$
r_{j}= \pm \sqrt{\frac{1}{2 r_{0} \beta_{1}}\left[\left(\beta_{1} \beta_{2}+r_{0} \beta_{3}-\eta_{1} \eta_{2}\right) \pm \sqrt{\left(\beta_{1} \beta_{2}+r_{0} \beta_{3}-\eta_{1} \eta_{2}\right)^{2}-4 r_{0} \beta_{1} \beta_{2} \beta_{3}}\right]}
$$

$$
\text { for } j=3,4
$$

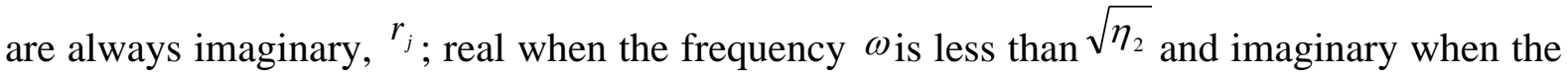
frequency is greater than $\sqrt{\eta_{2}}$. We call this cutoff frequency or the critical frequency $\omega_{c}$. Therefore, we must consider two cases when obtaining spatial solutions: (i.e $\omega \leq \omega_{c}$ and $\omega>\omega_{c}$ ). By using the four eigenvalues given by Equation (11), the spatial solution can be written as follows:

(a) When $0<\omega \leq \omega_{c}$

$$
\mathbf{V}(x) \equiv\left\{\begin{array}{l}
U(x) \\
\Phi(x)
\end{array}\right\}=\sum_{i=1}^{4} d_{i} \mathbf{v}_{i} e^{r_{i} x}=d_{1} \mathbf{u}_{1} e^{b x}+d_{2} \mathbf{u}_{2} e^{-b x}+d_{3} \mathbf{u}_{3} e^{i a x}+d_{4} \mathbf{u}_{4} e^{-i a x}
$$

(b) When $\omega>\omega_{c}$

$$
\mathbf{V}(x) \equiv\left\{\begin{array}{l}
U(x) \\
\Phi(x)
\end{array}\right\}=\sum_{i=1}^{4} \bar{d}_{i} \mathbf{v}_{i} e^{r_{i} x}=d_{1} \mathbf{u}_{1} e^{\bar{b} x}+d_{2} \mathbf{u}_{2} e^{-\bar{b} x}+d_{3} \mathbf{u}_{3} e^{i a x}+d_{4} \mathbf{u}_{4} e^{-i a x}
$$

where

$$
\begin{aligned}
& a=\sqrt{\frac{1}{2 r_{0} \beta_{1}}\left[\left(\eta_{1} \eta_{2}-\beta_{1} \beta_{2}-r_{0} \beta_{3}\right)+\sqrt{\left(\eta_{1} \eta_{2}-\beta_{1} \beta_{2}-r_{0} \beta_{3}\right)^{2}-4 r_{0} \beta_{1} \beta_{2} \beta_{3}}\right]} \\
& b=\sqrt{\frac{1}{2 r_{0} \beta_{1}}\left[-\left(\eta_{1} \eta_{2}-\beta_{1} \beta_{2}-r_{0} \beta_{3}\right)+\sqrt{\left(\eta_{1} \eta_{2}-\beta_{1} \beta_{2}-r_{0} \beta_{3}\right)^{2}-4 r_{0} \beta_{1} \beta_{2} \beta_{3}}\right]} \\
& c=\sqrt{\frac{1}{2 r_{0} \beta_{1}}\left[\left(\eta_{1} \eta_{2}-\beta_{1} \beta_{2}-r_{0} \beta_{3}\right)+\sqrt{\left(\eta_{1} \eta_{2}-\beta_{1} \beta_{2}-r_{0} \beta_{3}\right)^{2}-4 r_{0} \beta_{1} \beta_{2} \beta_{3}}\right]}
\end{aligned}
$$

By using the results, Equations (15) and (16) can be written in terms of sinusoidal and hyperbolic function as follows:

(a) When $0<\omega \leq \omega_{c}$

$$
\left\{\begin{array}{l}
U(x) \\
\Phi(x)
\end{array}\right\}=A_{1}\left\{\begin{array}{l}
\sin (a x) \\
g_{a} \cos (a x)
\end{array}\right\}+A_{2}\left\{\begin{array}{l}
\cos (a x) \\
-g_{a} \sin (a x)
\end{array}\right\}+A_{3}\left\{\begin{array}{l}
\sinh (a x) \\
g_{a} \cosh (a x)
\end{array}\right\}+A_{1}\left\{\begin{array}{l}
\cosh (b x) \\
g_{a} \sin (b x)
\end{array}\right\}
$$


(b) When $\omega>\omega_{c}$

$$
\left\{\begin{array}{l}
U(x) \\
\Phi(x)
\end{array}\right\}=A_{1}\left\{\begin{array}{l}
\sin (a x) \\
g_{a} \cos (a x)
\end{array}\right\}+A_{2}\left\{\begin{array}{l}
\cos (a x) \\
-g_{a} \sin (a x)
\end{array}\right\}+A_{3}\left\{\begin{array}{l}
\sinh (a x) \\
g_{a} \cosh (a x)
\end{array}\right\}+A_{1}\left\{\begin{array}{l}
\cosh (b x) \\
g_{a} \sin (b x)
\end{array}\right\}
$$

where

$$
g_{a}=\frac{1}{a \eta_{1}}\left(\beta_{1} a^{2}+K_{1}-\omega^{2}\right) ; g_{b}=\frac{1}{b \eta_{1}}\left(\beta_{1} b^{2}-K_{1}+\omega^{2}\right) ; g_{\bar{b}}=\frac{1}{\bar{b} \eta_{1}}\left(\beta_{1} \bar{b}^{2}+K_{1}-\omega^{2}\right)
$$

The present spatial solutions (20) and (21) are now the expressions for three frequency ranges $0<\omega \leq \omega_{c}$ and $\omega>\omega_{c}$.

\section{Natural Frequency and Mode Shape}

Analytical closed forms of natural frequencies and mode shapes are obtained for specific boundary condition; our present study is limited to simply supported conditions given by

$$
u(0, t)=u(L, t)=0 ; E I \frac{\partial \phi(L, t)}{\partial x}=0
$$

We consider just one frequency range as follows:

\subsubsection{When $0<\omega<\omega_{c}$}

Substituting Equation (20) into Equation (23) yields a matrix equation

$$
\left\{\begin{array}{l}
U(0) \\
\Phi^{\prime}(0) \\
U(L) \\
\Phi^{\prime}(L)
\end{array}\right\}=\left[\begin{array}{cccc}
0 & 1 & 0 & 1 \\
0 & -a g_{a} & 0 & b g_{b} \\
\sin (a L) & \cos (a L) & \sinh (b L) & \cosh (b L) \\
-a g_{a} \sin (a L) & -a g_{a} \cos (a L) & b g_{b} \sinh (b L) & b g_{b} \sinh (b L)
\end{array}\right]\left\{\begin{array}{l}
A_{1} \\
A_{2} \\
A_{3} \\
A_{4}
\end{array}\right\}=\left\{\begin{array}{l}
0 \\
0 \\
0 \\
0
\end{array}\right\}
$$

For existence of a non-trivial solution of $A_{i},(i=1,2,3,4)$ in Equation (24), the determinant of the matrix of eigenvalue problem must vanish. Thus, we obtain

$$
A_{2}=A_{4}=0 \text { and }\left(a g_{a}+b g_{b}\right) \sin (a L) \sinh (b L)
$$

Since $\left(a g_{a}+b g_{b}\right)=\neq 0$ and $\sinh (b L) \neq 0$, then if $0<\omega<\omega_{c}$ we have

$$
\sin \left(a_{n} L\right)=0
$$


from which we obtain

$$
a_{n}=\frac{n \pi}{L}\left(n=1,2,3, \ldots, n_{a}\right)
$$

Therefore, substituting Equation (27) into Equations (17) - (19) yields natural frequencies $\omega_{n}$ given as

$$
\omega_{a(n)}=\sqrt{Z(n)-\sqrt{Z(n)^{2}-4 R(n)}} \quad\left(n, 1,2,3, \ldots, n_{a}\right)
$$

where

$$
Z(n)=\frac{1}{2}\left[\left(\eta_{2}+K_{1}\right)-\left(\frac{n \pi}{L}\right)^{2}\left(r_{0}+\beta_{1}\right)\right] R(n)=\frac{1}{4}\left(\frac{n \pi}{L}\right)^{2}\left[r_{0} \beta_{1}\left(\frac{n \pi}{L}\right)^{2}+\eta_{1} \eta_{2}-\eta_{2} \beta_{1}-r_{0} K_{1}\right]
$$

Next, we obtain the mode shapes corresponding to the natural frequencies $\omega_{a}(n)\left(n=1,2, \ldots, n_{a}\right)$ by determining the values of $A_{1}$ and $A_{3}$ from Equation (24) in the following forms:

$$
A_{1}(n) \neq 0 ; A_{3}(n)=0
$$

Thus, the nth mode shape corresponding to $\omega_{a}(n)$ from equation (21) is written as

$$
\begin{array}{r}
\mathbf{V}_{a(n)}(x) \equiv\left\{\begin{array}{l}
U(x) \\
\Phi(x)
\end{array}\right\}=A_{a(n)}=\left\{\begin{array}{c}
\sin \frac{n \pi x}{L} \\
g_{a(n)} \cos \frac{n \pi x}{L}
\end{array}\right\} \\
\left(n=1,2, \ldots, n_{a}\right)
\end{array}
$$

where

$$
g_{a(n)}=\frac{L}{n \pi \eta_{1}}\left[\beta_{1}\left(\frac{n \pi x}{L}\right)^{2}+K_{1}-\omega_{a(n)}^{2}\right]
$$

Thus, in this study, we need to consider the following type of mode shape for the transverse vibration of the simply supported non-uniform prestressed thick beam on an elastic foundation.

$\mathrm{V}_{a(n)}(x)=A_{a(n)}=\left\{\begin{array}{c}\sin \frac{n \pi x}{L} \\ g_{a(n)} \cos \frac{n \pi x}{L}\end{array}\right\} \quad\left(\bmod e\right.$ shape for $\left.\omega_{a(n)}\right)$ 


\section{The Orthogonality Conditions for the Model}

In order to obtain the forced response of a thick beam, we set the method of eigenfunctions expansion. Therefore, the Orthogonality conditions of the eigenfunctions have to be established for the beam model discussed so far. Thus, the spatial equations of the homogeneous problem (9) can be written in the form

$$
\mathrm{K}\left(V_{n}\right)=\omega_{n}^{2} \mathbf{M}\left(V_{n}\right)
$$

where $V_{n}$ denotes the nth eigenfunctions for the vector $\left[U_{n} \Phi_{n}\right]^{T}$ of the beam model and corresponding to the natural frequency $\omega_{n}^{2}$ uniquely within an arbitrary constant. The operators $\mathbf{K}$ and $\mathbf{M}$ are self-adjoint (with corresponding boundary conditions) if

$$
\int_{0}^{L}\left[V_{n}^{T} K\left(V_{m}\right)-V_{m}^{T} K\left(V_{n}\right)\right] d x=0
$$

and

$$
\int_{0}^{L}\left[V_{n}^{T} M\left(V_{m}\right)-V_{m}^{T} M\left(V_{n}\right)\right] d x=0
$$

Since the condition in Equation (36) is automatically satisfied for the model, then using Equation (34), we can write the condition in Equation (35) as

$$
\left(\omega_{n}^{2}-\omega_{n}^{2}\right) \int_{0}^{L} V_{n}^{T} M\left(V_{m}\right)=0
$$

However, eigenvalues are unique to the eigenfunctions, $\omega_{m}^{2} \neq \omega_{n}^{2}$ for $(m \neq n)$. In order for the above equation to be zero, the integral has to be zero, i.e.

$$
\int_{0}^{L} V_{n}^{T} M\left(V_{m}\right)=0 \quad(\text { for } m \neq n)
$$

This is the Orthogonality condition for the eigenfunctions. When $m=n$, we normalize the eigenfunctions by setting the integral equal to one

$$
\int_{0}^{L} V_{n}^{T} M\left(V_{m}\right)=1 \quad(\text { for } n=1,2,3, \ldots)
$$

Combining Equations (38) and (39), we can write

$$
\int_{0}^{L} V_{n}^{T} M\left(V_{m}\right)=\delta_{m n}
$$


where $\delta_{m n}$ is the Kronecker delta.

For this model, the corresponding boundary conditions for the self-adjoint operator $\mathrm{K}$ are found to be

$$
\left.\varphi G A\left[U_{n}\left(\frac{d U_{m}}{d x}-\Phi_{m}\right)-U_{m}\left(\frac{d U_{n}}{d x}-\Phi_{n}\right)\right]\right|_{0} ^{L}+\left.\left[\Phi_{n} \frac{d \Phi_{m}}{d x}-\Phi_{m} \frac{d \Phi_{n}}{d x}\right]\right|_{0} ^{L}
$$

Then, substituting Equation (33) into Equation (39), we derive the coefficient of normal mode shape as

$$
A_{a(n)}=\sqrt{\frac{2}{L\left(1+g_{a(n)}^{2}\right)}}
$$

\section{Modal Analysis of Forced Vibration of the Model}

The forced vibration of equation (1) can be represented by using the mode summation given as

$$
\mathbf{v}(x, t)=\sum_{n=1}^{\infty} V_{a(n)}(x) y_{a(n)}(t)
$$

where $\mathbf{v}(x, t)$ stands for $[u(x, t) \phi(x, t)]^{T}$ in this model while ${ }^{y_{a(n)}(t)}$ is the generalized timedependent coordinates to be determined in order to satisfy initial boundary conditions. Therefore, substituting Equation (43) into Equation (1) and applying the Orthogonality conditions of the normal mode shapes yield the following equation:

$$
\mathrm{MV}_{\mathrm{a}(n)} \frac{d^{2} y_{a(n)}(x, t)}{d t^{2}}+\mathrm{KV}_{\mathrm{a}(n)} y_{a(n)}=f_{a(n)}
$$

where the generalized force is defined as

$$
f_{a(n)}=\int_{0}^{L} V_{a(n)}(x) f(x, t) d x
$$

where $f(x, t)$ is the distributed harmonic load parameter. For this problem, the distributed load moving on the beam has mass commensurable with the mass of the beam. Consequently, the load inertia is not negligible but significantly affects the behavior of the dynamical system. Thus, the distributed load $F(x, t)$ takes the form

$$
F(x, t)=\cos (\alpha t) M_{0} g H\left[x-c t\left[1-\frac{1}{g}\left(\frac{\partial^{2}}{\partial t^{2}}+2 c \frac{\partial^{2}}{\partial x \partial t}+c^{2} \frac{\partial^{2}}{\partial x^{2}}\right)\right] u(x, t)\right]
$$


where $P_{0}$ is the magnitude of the transverse distributed force, $g$ is the acceleration due to gravity, $c$ is the initial velocity, $H[x-c t]_{\text {is }}$ the Heaviside function which is a typical engineering function made to measure engineering applications involving functions that are either "on" of "off". Therefore, incorporating Equations (45) and (46) into Equation (44), and thereafter evaluating the integrals with the use of Fourier sine series representation of the Heaviside function yields the following equations:

$$
\begin{gathered}
\frac{d^{2} y_{a(n)}}{d t^{2}}+\omega_{(n)}^{2} y_{a(n)}(t)+\varepsilon_{a} \cos (w t)\left\{\left[\frac{L}{8}+\frac{L}{\pi} \sum_{n=0}^{\infty} \frac{\cos (2 n+1) \pi c t}{2 n+1} I_{6 a}(m, n)\right.\right. \\
\left.-\frac{L}{\pi} \sum_{n=0}^{\infty} \frac{\sin (2 n+1) \pi c t}{2 n+1} I_{6 b}(m, n)\right] \ddot{y}_{a(n)}(t)+2 c\left(\frac{n \pi}{L}\right)\left[\frac{I_{7 a}(m n)}{4}+\frac{1}{\pi} \sum_{n=0}^{\infty} \frac{\cos (2 n+1) \pi c t}{2 n+1} I_{7 b}(m, n)\right. \\
\left.-\frac{L}{\pi} \sum_{n=0}^{\infty} \frac{\sin (2 n+1) \pi c t}{2 n+1} I_{7 c}(m, n)\right] \dot{y}_{a(n)}(t)-c^{2}\left(\frac{n \pi}{L}\right)^{2}\left[\frac{L}{8}+\frac{1}{\pi} \sum_{n=0}^{\infty} \frac{\cos (2 n+1) \pi c t}{2 n+1} I_{6 a}(m, n)\right. \\
\left.\left.\frac{1}{\pi} \sum_{n=0}^{\infty} \frac{\sin (2 n+1) \pi c t}{2 n+1} I_{6 a}(m, n)\right] y_{a(n)}(t)\right\}=P_{a(n)}\left[\cos \theta_{n} t-R_{n}\right]
\end{gathered}
$$

where

$$
\begin{aligned}
& \omega_{(n)}^{2}=\left[\frac{n^{2} \pi^{2}}{L}\left(\frac{L}{2} \beta_{1}+K_{N} I_{1}\right)+\frac{1}{2}\left(r_{0}\left(\frac{n \pi}{L}\right)^{2}+\eta_{2}-\eta_{2}\left(\frac{n \pi}{g_{a(n)} L}\right)\right)-\left(\frac{n \pi^{3}}{L^{3}}\right) K_{N} I_{2}\right. \\
& \left.+0.5 K_{1}-\eta_{1}\left(\frac{n \pi}{2 L g_{a(n)}}\right)\right] ; \quad I_{1}=\int_{0}^{L} \sin \frac{\pi x}{L} \sin \frac{n \pi x}{L} \sin \frac{m \pi x}{L} d x \\
& I_{2}=\int_{0}^{L} \cos \frac{\pi x}{L} \cos \frac{n \pi x}{L} \sin \frac{m \pi x}{L} d x, \varepsilon_{a}=\frac{M_{0}}{\rho A L} ; P_{a(n)}=\frac{M_{0} g \cos (w t)}{A_{a(n)} \rho A n \pi} \\
& \theta_{n}=\frac{n \pi c}{L} ; R_{n}=-(-1)^{n} ; I_{6 a}=\int_{0}^{L} \sin (2 n+1) \sin \frac{n \pi x}{L} \sin \frac{m \pi x}{L} d x \\
& I_{6 b}=\int_{0}^{L} \cos (2 n+1) \sin \frac{n \pi x}{L} \sin \frac{m \pi x}{L} d x, I_{6 a}=\int_{0}^{L} \cos (2 n+1) \sin \frac{n \pi x}{L} \sin \frac{m \pi x}{L} d x
\end{aligned}
$$

Equation (47) now represents the transformed governing equations for the simply supported non-uniform prestressed Timoshenko beam resting on an elastic foundation under distributed harmonic moving load. By considering Equation (47), we can derive the responses of the beam for two cases:

Case I: When the beam is subjected to a load of negligible inertia, i.e. by setting $\varepsilon_{a}=0$. This is termed moving force problem.

Case II: When the beam is subjected to a load of non-negligible inertia, i.e. when ${ }_{a}$ is greater than zero. This is termed moving mass problem. 


\section{Modal Analysis of Forced Vibration of the Model when the Beam is Traversed by Moving Force}

In this section, an approximate model of the differential equation describing the response of a uniform Timoshenko beam resting on Pasternak foundation and under the action of a moving distributed force is obtained by neglecting inertia terms, that is $\varepsilon_{a}=0$. equation (47) is now of the form

$$
\ddot{y}_{a(n)}(t)+\omega_{(n)}^{2} y_{a(n)}=W_{a}(t)
$$

where

$$
W_{a}(t)=P_{a(n)}\left[\cos \theta_{n} t+R_{n}\right]
$$

Therefore, solving equation (49) using the method of Laplace transforms in conjunction with the convolution theory for unknown generalized coordinates ${ }^{y_{a(n)}}$ and then substituted the results into Equation (43) to obtain the vibration responses as follows:

$$
\mathbf{v}(x, t)=\sum_{n=1}^{\infty} \frac{\mathrm{V}_{\mathrm{a}(n)}(x)}{\omega_{(n)}}\left[\int_{0}^{t} W_{a}(t) \sin \omega_{(n)}(t-\tau) d \tau+y_{a(n)}\left((0) \cos \omega_{(n)} t+\frac{1}{\omega_{(n)}} \dot{y}_{a(n)}(0)\right]\right.
$$

Thus, Equation (51) represents the solution to forced vibration of non-uniform prestressed Timoshenko beams resting on an elastic foundation under distributed harmonic moving load for moving force case.

\section{Modal Analysis of Forced Vibration of the Model when the Beam is Traversed by Moving Mass}

In this section, the solution of the entire Equation (47) is sought when no terms of the couple differential equation is neglected. Evidently, an exact solution to this equation is not possible. All conventional methods break down; even the popular Struble's technique cannot handle it because of the variability of the magnitude of the moving harmonic load; hence, we resort to Runge-Kutta method. Thus, Equation (47) takes the form

$$
\ddot{y}_{a(n)}(t)+\frac{2 \varepsilon_{a} c Q_{2}(m, n)}{1+\varepsilon_{a} Q_{1}(m, n)} \dot{y}_{a(n)} t+\frac{\omega_{a(n)}^{2}+\varepsilon_{a} c^{2} Q_{2}(m, n)}{1+\varepsilon_{a} Q_{1}(m, n)} y_{a(n)} t=\frac{P_{a(n)}\left[\cos \theta_{k} t+R_{n}\right]}{1+\varepsilon_{a} Q_{1}(m, n)}
$$

where

$$
\begin{gathered}
Q_{1}(m, n)=\left[\frac{L}{8}+\frac{L}{\pi} \sum_{n=0}^{\infty} \frac{\cos (2 n+1) \pi c t}{2 n+1} I_{6 a}(m, n)-\frac{L}{\pi} \sum_{n=0}^{\infty} \frac{\sin (2 n+1) \pi c t}{2 n+1} I_{6 b}(m, n)\right] \\
Q_{2}(m, n)=\left(\frac{n \pi}{L}\right)\left[\frac{I_{7 a}(m, n)}{4}+\frac{1}{\pi} \sum_{n=0}^{\infty} \frac{\cos (2 n+1) \pi c t}{2 n+1} I_{7 a}(m, n)-\frac{1}{\pi} \sum_{n=0}^{\infty} \frac{\sin (2 n+1) \pi c t}{2 n+1} I_{7 c}(m, n)\right] \\
Q_{3}(m, n)=\left(\frac{n \pi}{L}\right)^{2} Q_{1}(m, n)
\end{gathered}
$$


Therefore, solving Equation (52) using Runge-Kutta method for unknown generalized coordinates $^{y_{a(n)}}$ and then substituting the results into Equation (43) yields

$$
\mathbf{v}(x, t)=\sum_{\mathrm{n}=1}^{\infty} \mathrm{V}_{\mathrm{a}(\mathrm{n})}(x) y_{a(n)}(t)
$$

Thus, Equation (51) represents the solution to forced vibration of non-uniform prestressed Timoshenko beams resting on an elastic foundation, under distributed harmonic moving load for moving mass case.

\section{NUMERICAL INVESTIGATION}

In order to investigate the dynamic response of the present study, we reconsidered the uniform simply supported Timoshenko beam that was previously employed by Esmalizedeh and Ghorashi [7]. The geometric and material properties data of the beam are as follows: length $L=27.374 \mathrm{~m}$, area moment of inertia $I=5.71 \times 10^{-7} \mathrm{~m}^{4}$, cross-sectional area $A=3.3183 \times 10^{-5}$, Young modulus $E=2.02 \times 10^{11} \mathrm{Nm}^{2}$, shear modulus $G=7.7 \times 10^{10} \mathrm{Nm}^{-2}$, mass density $\rho=15267 \mathrm{~kg} / \mathrm{m}^{3}$ and shear correction factor taken as $\varphi=0.7$. For the analyses of forced vibrations, we assumed that the mass $M_{0}=454.08 \mathrm{~kg}$ and $g=9.8 \mathrm{~ms}^{-2}$. We assumed that the beam has null initial conditions.

\section{Model Verification}

In this subsection, we aim to verify the accuracy of the present method MA. Thus, the eigenfrequency and the dynamic response of the simply supported (SS) beam is computed and compared to the existing literature. Following the work of Tachyum Kim et al. (2017), we compare the natural frequencies and mode shape of the present work.

Table 1: Frequency parameter of SS thick beam on an elastic foundation at various values of the Mode number ${ }^{(n)}$

\begin{tabular}{|c|c|c|c|c|}
\hline $\begin{array}{c}\text { Mode } \\
\left(K_{0}=0, N_{0}=0\right)\end{array}$ & $g_{a}$ & $\omega_{a(n)}$ & $\begin{array}{c}\text { Tachyum } \\
g_{a}(2017)\end{array}$ & $\begin{array}{c}\omega_{a(n)} \\
2017\end{array}$ \\
\hline 1 & 0.70 & 6.29 & 0.72 & 6.29 \\
2 & 1.21 & 25.19 & 1.44 & 25.14 \\
3 & 1.51 & 56.84 & 2.15 & 56.41 \\
4 & 1.93 & 101.43 & 2.86 & 99.92 \\
5 & 3.28 & 159.28 & 3.53 & 155.39 \\
\hline Mode $^{(n)}$ & $g_{a}$ & $\omega_{a(n)}$ & Tachyum & $\omega_{a(n)}$ \\
$\left(K_{0}=0, N_{0}=400\right)$ & & & $g_{a}(2017)$ & 2017 \\
\hline 1 & 0.70 & 5.40 & 0.72 & 6.29 \\
2 & 1.21 & 24.35 & 1.44 & 25.14 \\
3 & 1.51 & 56.01 & 2.15 & 56.41 \\
4 & 1.93 & 100.61 & 2.86 & 99.92 \\
5 & 3.28 & 158.46 & 3.53 & 155.39 \\
\hline
\end{tabular}




\begin{tabular}{|c|c|c|c|c|}
\hline $\begin{array}{c}\text { Mode }^{(n)} \\
\left(K_{0}=40 Q N_{0}=0\right)\end{array}$ & $g_{a}$ & $\omega_{a(n)}$ & $\begin{array}{c}\text { Tachyum } \\
g_{a}(2017)\end{array}$ & $\begin{array}{c}\omega_{a(n)} \\
2017\end{array}$ \\
\hline 1 & 0.70 & 6.23 & 0.72 & 6.29 \\
2 & 1.21 & 25.14 & 1.44 & 25.14 \\
3 & 1.51 & 56.79 & 2.15 & 56.41 \\
4 & 1.93 & 101.38 & 2.86 & 99.92 \\
5 & 3.28 & 159.23 & 3.53 & 155.39 \\
\hline
\end{tabular}

It is seen from Table 1 that regardless of the values of axial force and foundation stiffness, the natural frequencies $\omega_{a(n)}$ and the corresponding mode shape parameter $g_{a}$ of the simply supported beam on the elastic foundation in the present work is in good agreement with that reported by [23], who computed the frequency parameter without considering both axial force and foundation stiffness.

Figure 1 shows the dynamic responses predicted at $x / L=0.25$, when the Timoshenko beam is subjected to a distributed force at its middle point $x / L=0.5$. The responses are the transverse displacement $u(0.25 L, t)$, the total slope $u^{\prime}(0.25 L, t)$, the slope due to bending $\phi(0.25 L, t)$ and the shear angle due to transverse shear force $\Psi(0.25 L, t)=u^{\prime}(0.25 L, t)-\phi(0.25 L, t)$. Figures (1-4) show the deformed shape at three different values of axial force $\left(N_{0}=0,4 \times 10^{5}, 4 \times 10^{8}\right)$ for the dynamic responses. As seen from the figures, the dynamic deflection of the beam decreases as the value of axial force increases. Figures (5-8) show the effect of the axial force on the dynamic response of the prestressed simply supported Timoshenko beam resting on a Winkler foundation at constant velocity $c=0.25 v_{c}$, (where $v_{c}$ is the lowest critical speed given as $v_{c}=2 \pi f_{1} L$ and $f_{1}$ is the first natural frequency in $\mathrm{Hz}$.) and different excitation frequencies $\alpha=0 \mathrm{rad} / \mathrm{s}$ and $\alpha=60 \mathrm{rad} / \mathrm{s}$ ). As seen from the figures, the dynamic deflection of the beams decreases with an increase in the values of axial force, regardless of the values of excitation frequency.

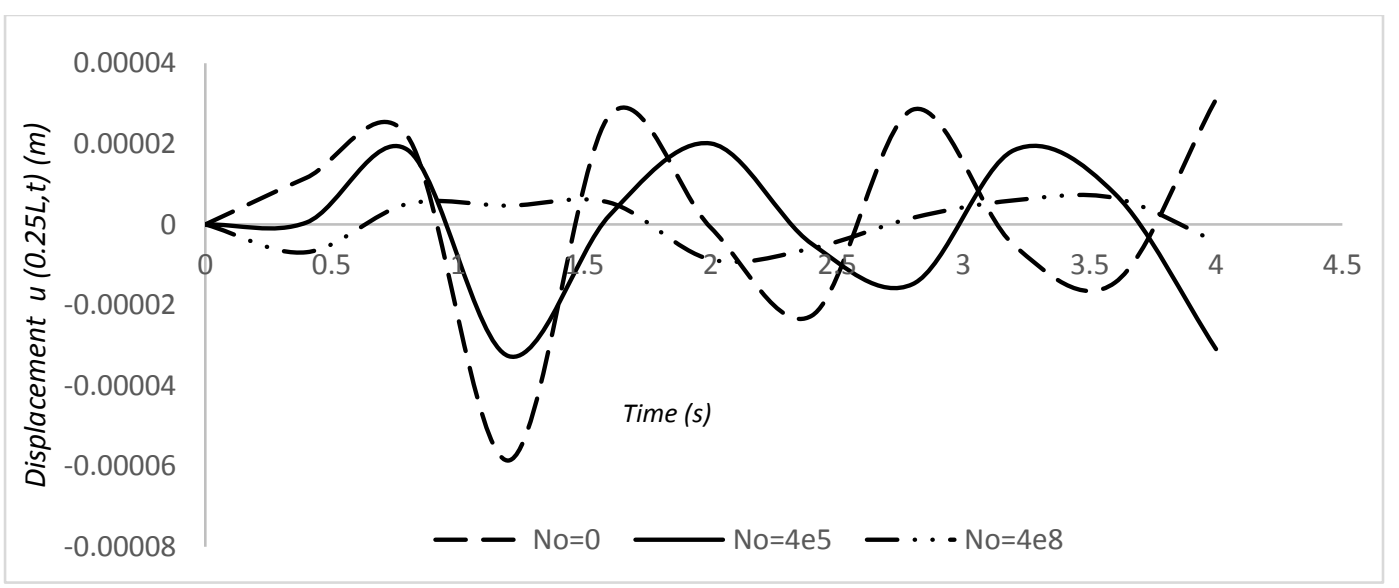

Figure 1: Dynamic response at $x / L=0.25$ of a simply supported beam subjected to a distributed mass applied at $x / L=0.5$ for the case of constant velocity $c=0.25 v_{c}$ when $N o=4 \times 10^{4}$, Ko $=4 \times 10^{3}$ and excitation frequency $\alpha=6.283$. 


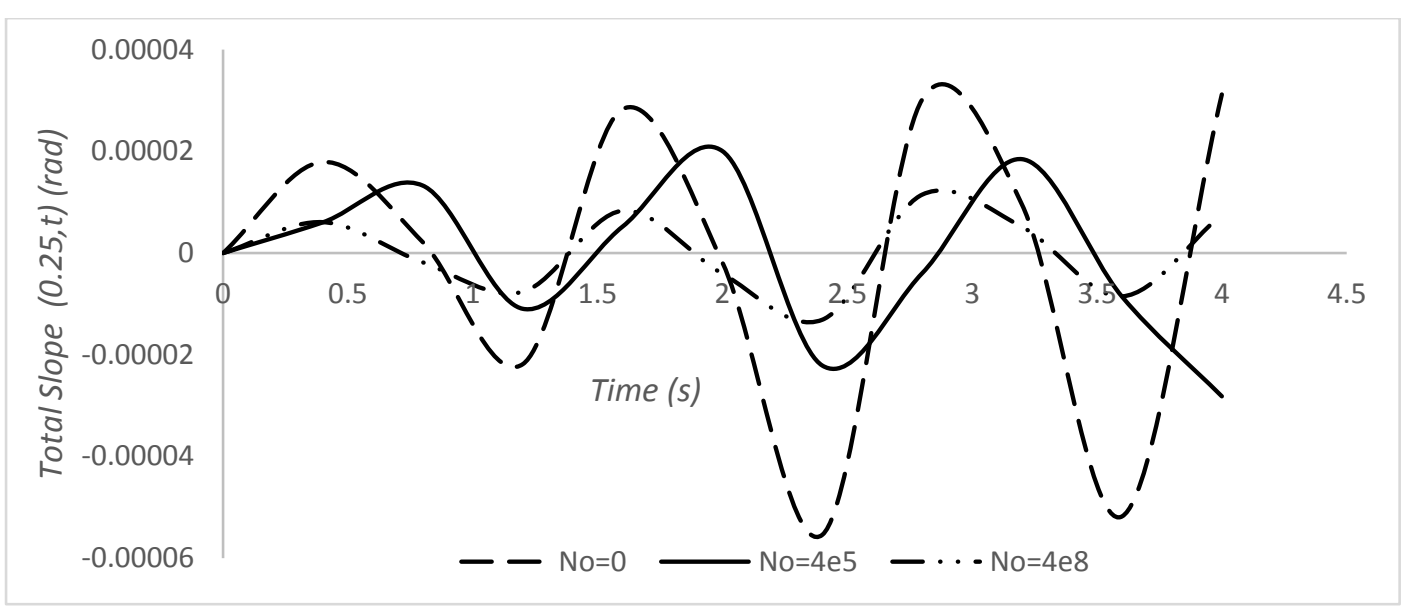

Figure 2: Dynamic response at $x / L=0.25$ of a simply supported beam subjected to a distributed mass applied at $x / L=0.5$ for the case of constant velocity $c=0.25 v_{c}$ when $N o=4 \times 10^{4}$, Ko $=4 \times 10^{3}$ and excitation frequency $\alpha=6.283$ for total slope $u^{\prime}$

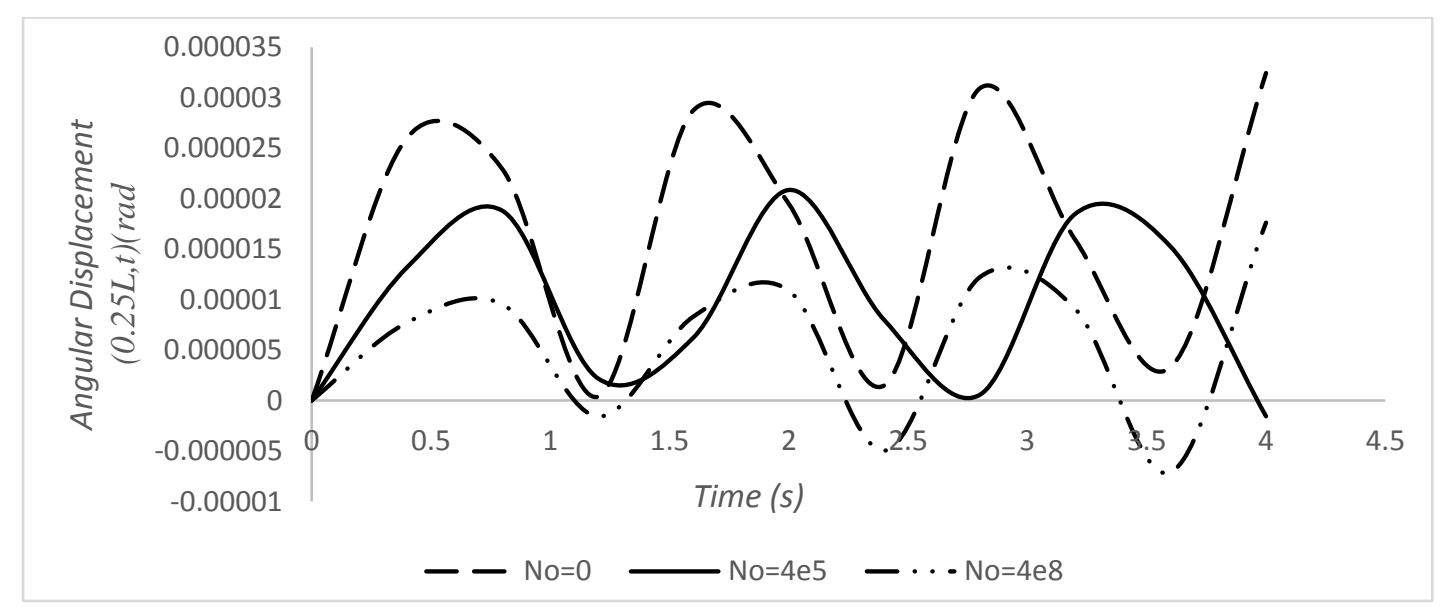

Figure 3: Dynamic response at $x / L=0.25$ of a simply supported beam subjected to a distributed mass applied at $x / L=0.5$ for the case of constant velocity $c=0.25 v_{c}$ when $N o=4 \times 10^{4}$, $K o=4 \times 10^{3}$ and excitation frequency $\alpha=6.283$ for slope due to bending $(\phi)$ 
African Journal of Mathematics and Statistics Studies

ISSN: 2689-5323

Volume 4, Issue 2, 2021 (pp. 66-87)

www.abjournals.org

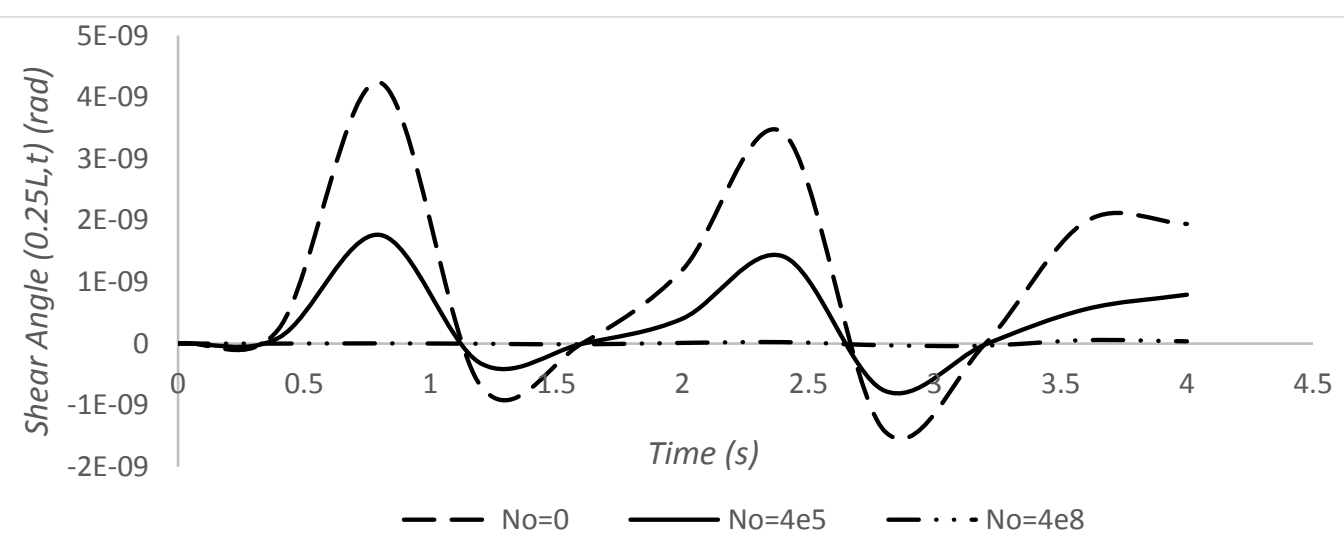

Figure 4: Dynamic response at $x / L=0.25$ of a simply supported beam subjected to a distributed mass applied at $x / L=0.5$ for the case of constant velocity $c=0.25 v_{c}$ when $N o=4 \times 10^{4}$, Ko $=4 \times 10^{3}$ and excitation frequency $\alpha=6.283$ for shear angle $(\Psi)$

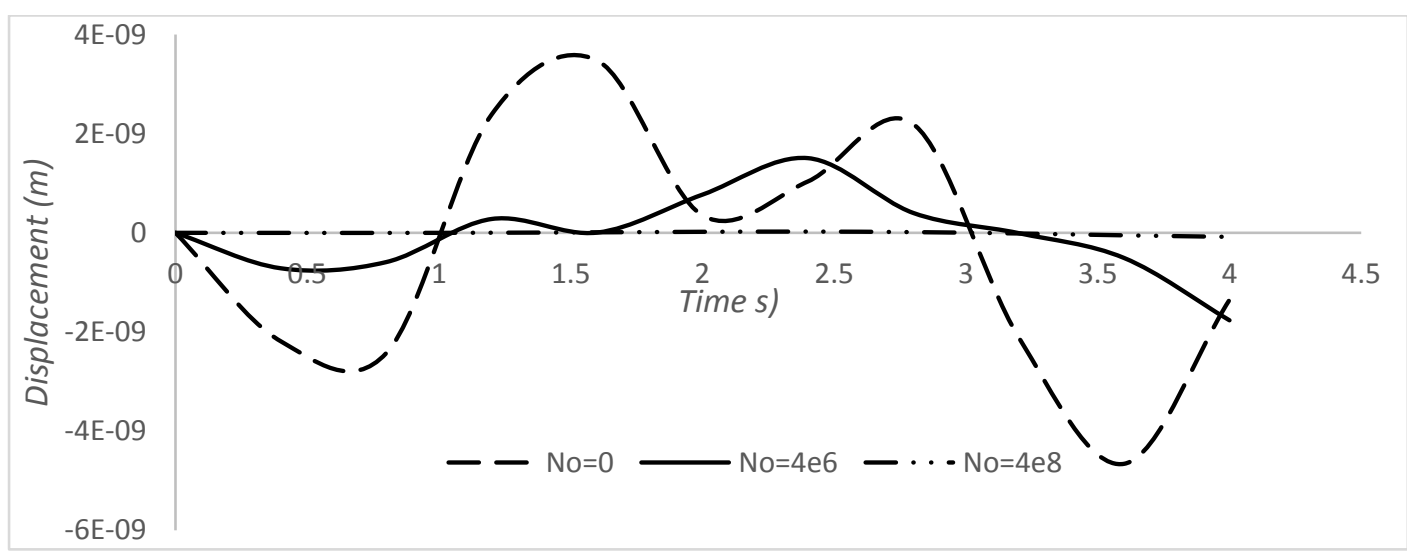

Figure 5: Effect of axial force No on the dynamic response at $x / L=0.25$ of a simply supported beam subjected to a distributed force applied at $x / L=0.5$ for the case of constant velocity $c=0.25 v_{c}$ when the excitation frequency $\alpha=8$ 
African Journal of Mathematics and Statistics Studies

ISSN: 2689-5323

Volume 4, Issue 2, 2021 (pp. 66-87)

www.abjournals.org

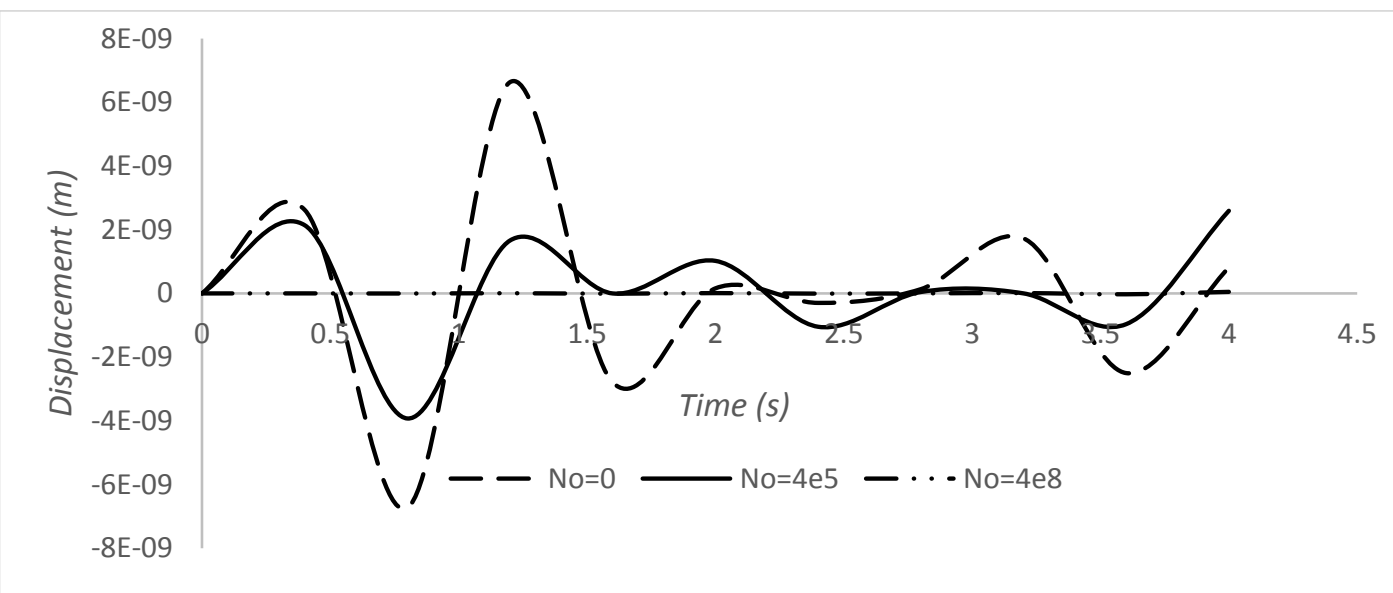

Figure 6: Effect of axial force No on the dynamic response at $x / L=0.25$ of a simply supported beam subjected to a distributed force applied at $x / L=0.5$ for the case of constant velocity $c=0.25 v_{c}$ when the excitation frequency $\alpha=32$

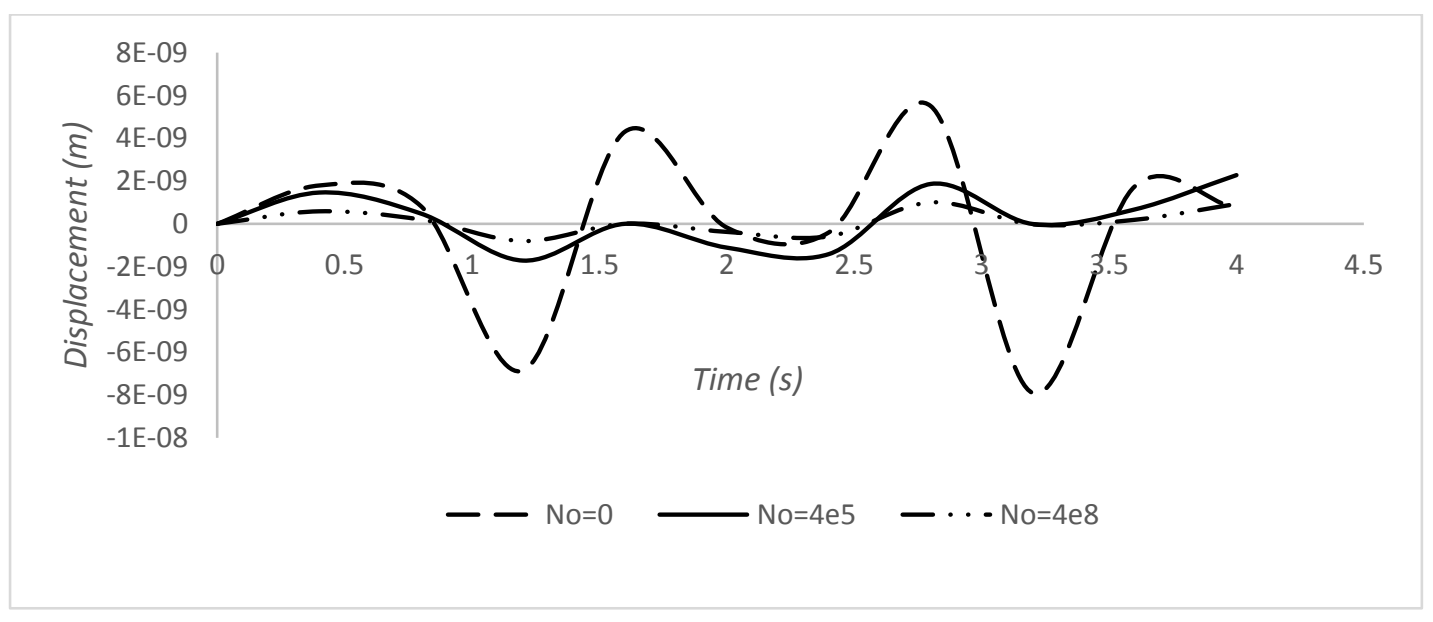

Figure 7: Effect of axial force No on the dynamic response at $x / L=0.25$ of a simply supported beam subjected to a distributed mass applied at $x / L=0.5$ for the case of constant velocity $c=0.25 v_{c}$ when the excitation frequency $\alpha=8$ 
African Journal of Mathematics and Statistics Studies

ISSN: 2689-5323

Volume 4, Issue 2, 2021 (pp. 66-87)

www.abjournals.org

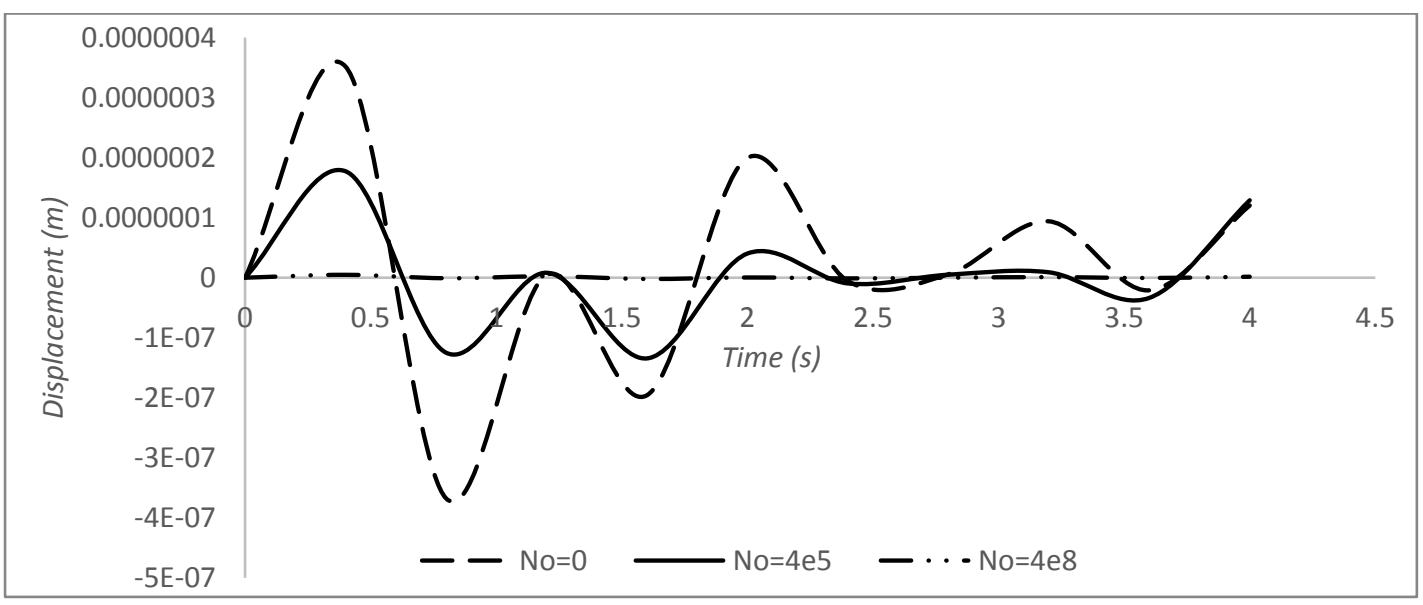

Figure 8: Effect of axial force No on the dynamic response at $x / L=0.25$ of a simply supported beam subjected to a distributed mass applied at $x / L=0.5$ for the case of constant velocity $c=0.25 v_{c}$ when the excitation frequency $\alpha=32$

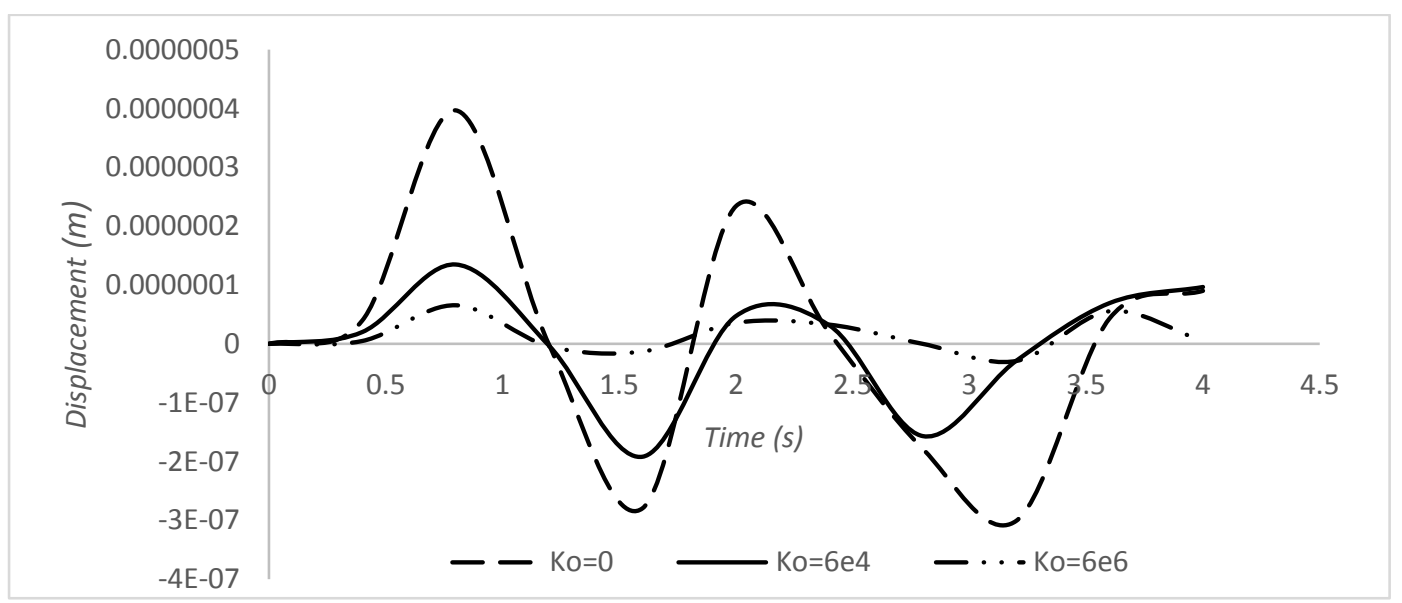

Figure 9: Effect of foundation stiffness Ko on the dynamic response at $x / L=0.25$ of a simply supported beam subjected to a distributed force applied at $x / L=0.5$ for the case of constant velocity $^{c}=0.25 v_{c}$ when the excitation frequency $\alpha=8$ 
African Journal of Mathematics and Statistics Studies

ISSN: 2689-5323

Volume 4, Issue 2, 2021 (pp. 66-87)

www.abjournals.org

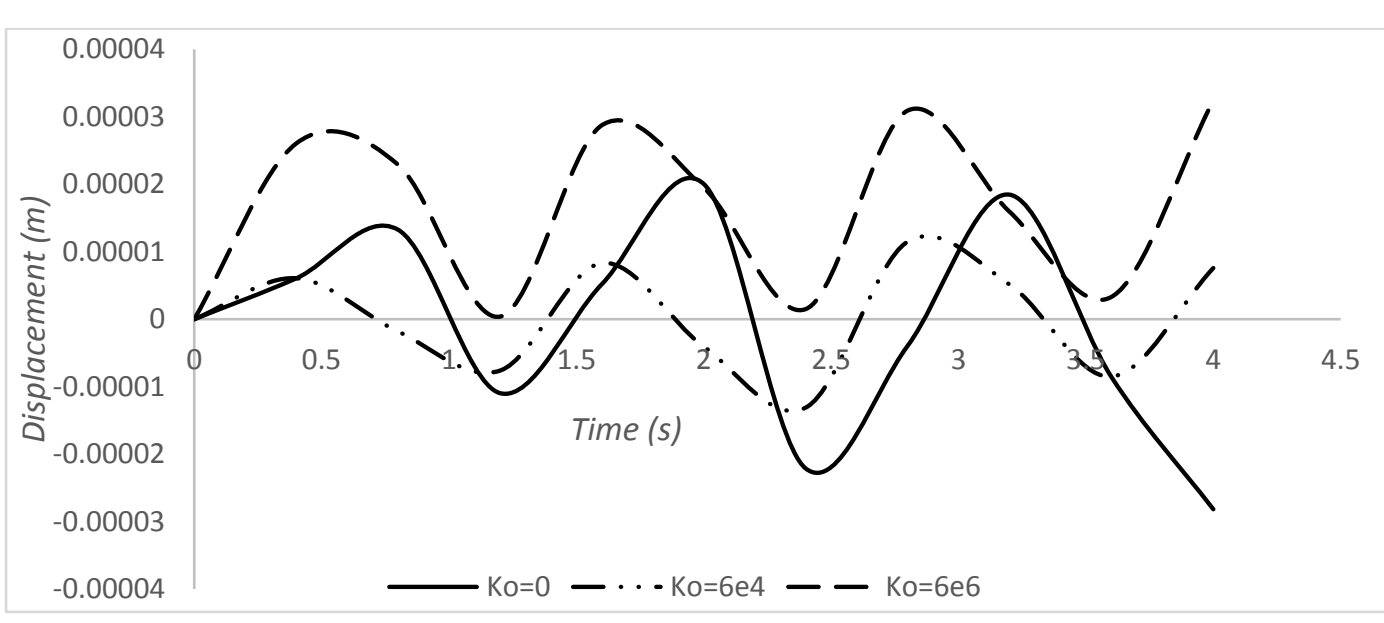

Figure 10: Effect of foundation stiffness Ko on the dynamic response at $x / L=0.25$ of a simply supported beam subjected to a distributed force applied at $x / L=0.5$ for the case of constant velocity $c=0.25 v_{c}$ when the excitation frequency $\alpha=32$

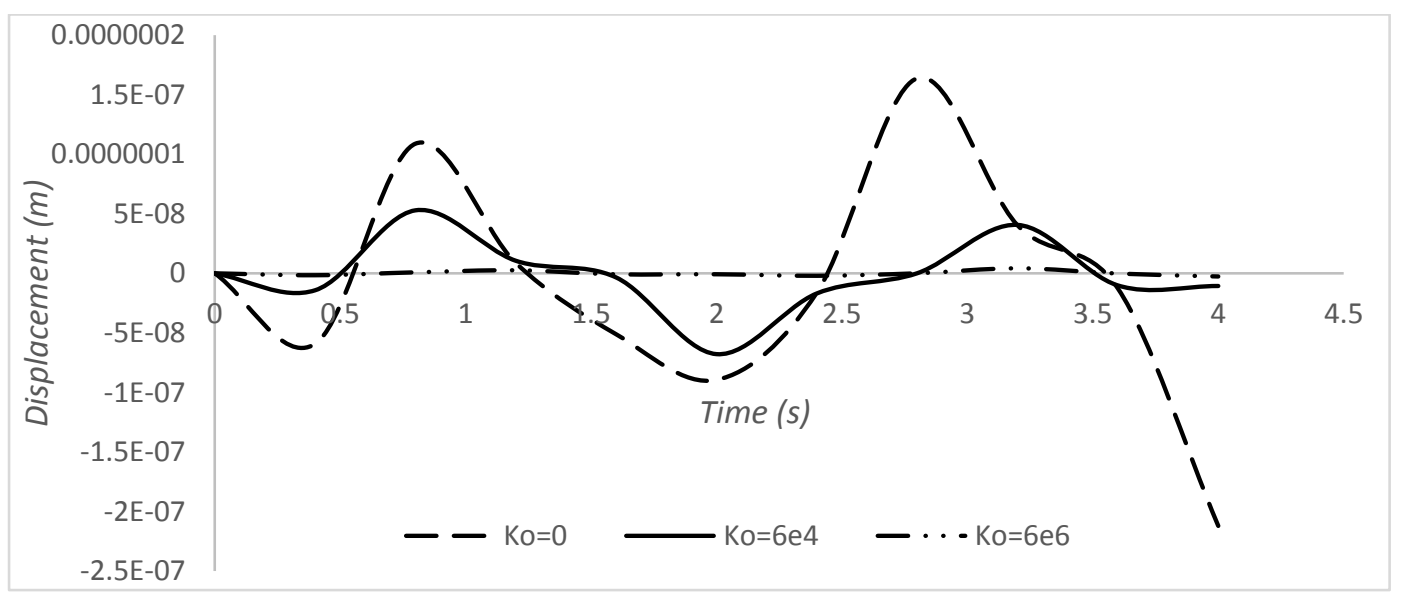

Figure 11: Effect of foundation stiffness Ko on the dynamic response at $x / L=0.25$ of a simply supported beam subjected to a distributed mass applied at $x / L=0.5$ for the case of constant velocity $c=0.25 v_{c}$ when the excitation frequency $\alpha=8$ 
African Journal of Mathematics and Statistics Studies

ISSN: 2689-5323

Volume 4, Issue 2, 2021 (pp. 66-87)

www.abjournals.org

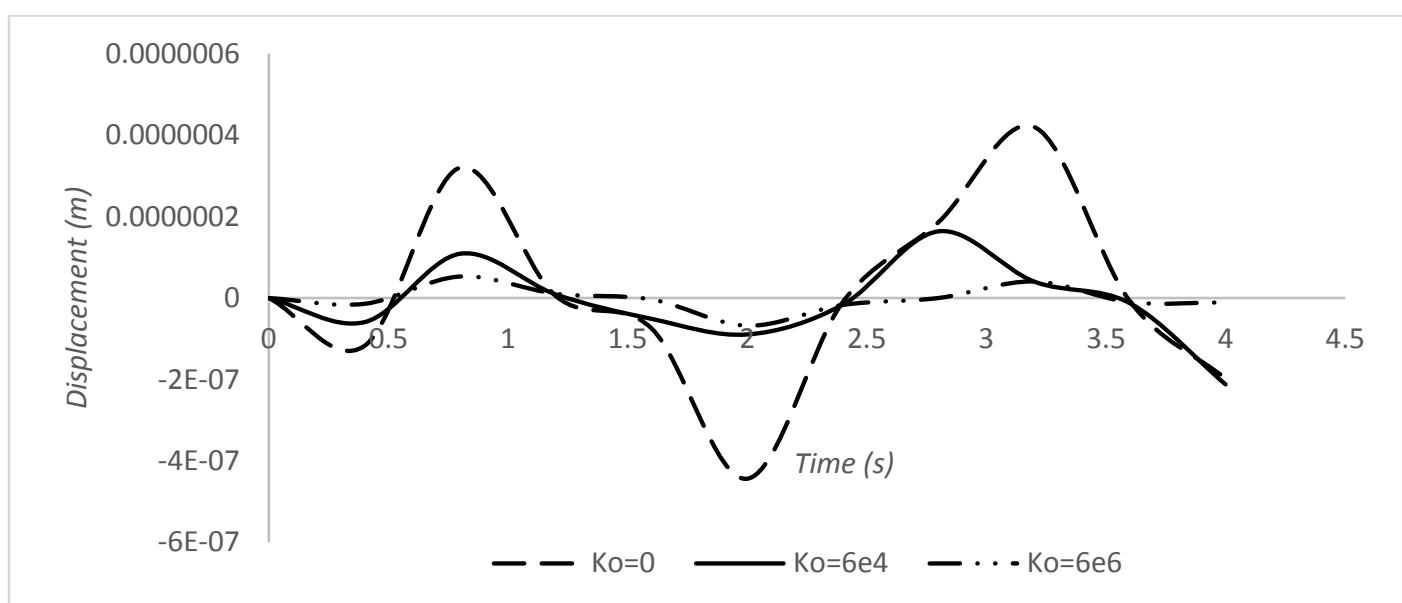

Figure 12: Effect of foundation stiffness Ko on the dynamic response at $x / L=0.25$ of a simply supported beam subjected to a distributed mass applied at $x / L=0.5$ for the case of constant velocity $c=0.25 v_{c}$ when the excitation frequency $\alpha=32$

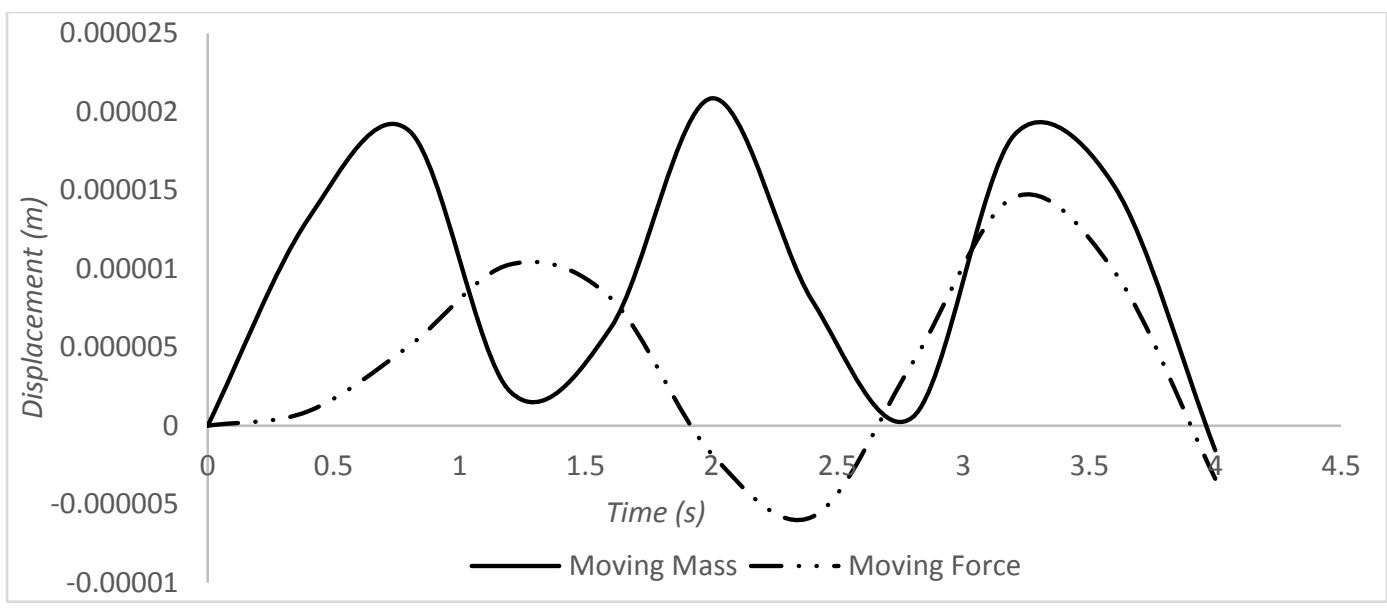

Figure 13: Comparison of the moving force and moving mass cases of transverse displacement of

the thick beam resting on non-uniform Vlasov foundation subjected to harmonic moving loads for fixed values of $N_{0}=4000$ and $K_{0}=4000$ when the excitation frequency $\alpha=8$ 


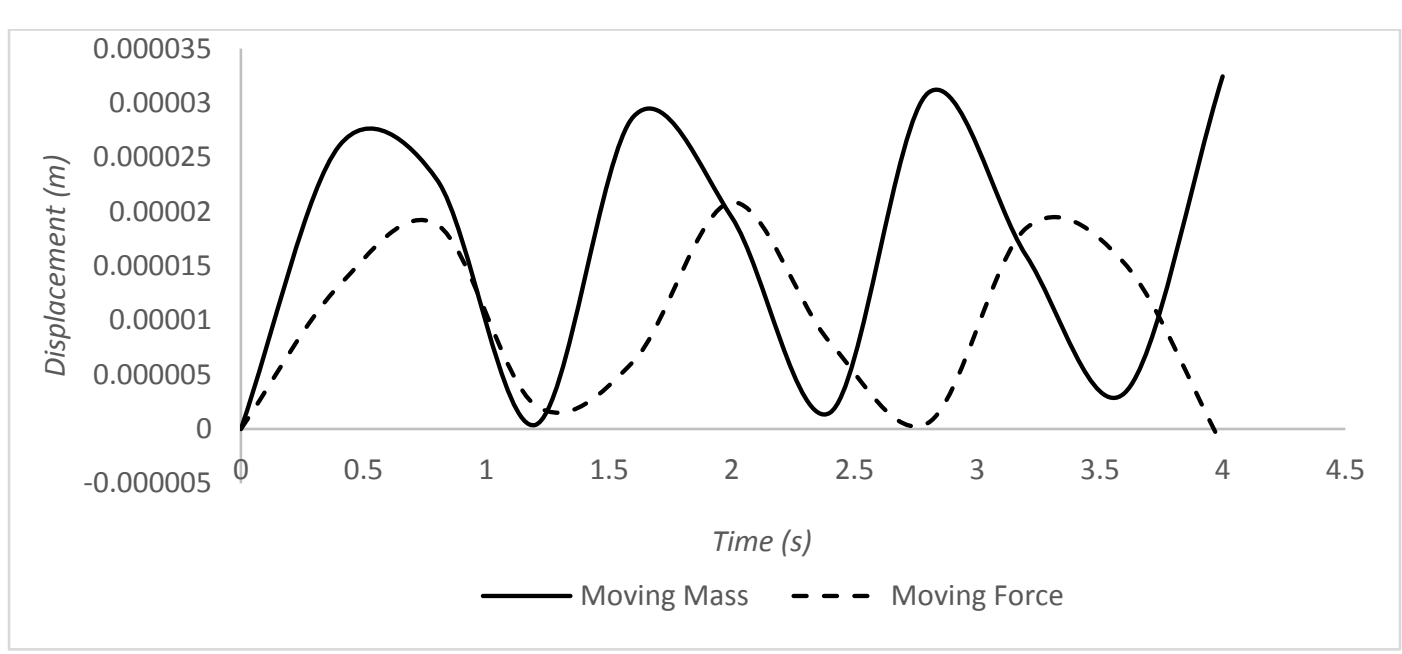

Figure 14: Comparison of the moving force and moving mass cases of transverse displacement of

the thick beam resting on non-uniform Vlasov foundation subjected to harmonic moving

loads for fixed values of $N_{0}=4000$ and $K_{0}=4000$ when the excitation frequency $\alpha=32$

Figures 9-12 show the effects of foundation stiffness on the dynamic response of the simply supported Timoshenko beam resting on a Winkler foundation for a moving mass case. As seen from the figures, the dynamic deflection of the beam decreases with an increase in the value of excitation frequency. The deflections of the beam are much more pronounced in the moving mass cases than in the moving force cases.

Finally, Figures 13 and 14 depict the comparison of the transverse displacement of moving distributed force and the moving distributed mass cases for simply supported beam traversed by harmonic moving distributed load for $G_{0}=4000$ and $K_{0}=4000$ at two different excitation frequencies. Clearly, the response amplitude of moving distributed mass is greater than that of moving distributed force; problems for the two excitation frequencies must be considered when heavy loads are involved. This shows that a moving distributed force solution is not always upper bound to the solution of a moving distributed mass problem.

\section{CONCLUSION}

The problem of dynamic response of non-prestressed Timoshenko beams resting on an elastic foundation subjected to harmonic moving loads using modal analysis (MA) was examined. The dynamic response of the simply supported beams for moving force and moving mass cases has been computed at different values of axial force, foundation stiffness and excitation frequency. The analyses exhibited the following features:

(i) The deformed shapes of Timoshenko beams strongly depend on the speeds of the moving load. There is a critical speed at which the dynamic system reaches a pick value, and this speed called critical speed is affected by the foundation stiffness and the excitation frequency. 
(ii) The effects of the moving velocity depend on the excitation frequency and this affects the dynamic deflection of the beam.

(iii) A set of natural frequencies and mode shapes are presented in closed forms for frequency range $0<\omega \leq \omega_{c}$ where $\omega_{c}$ is the cutoff frequency.

(iv) As the value of axial force and foundation stiffness increases, the transverse deflection of the beam model decreases. This strongly depends on the excitation frequency.

\section{REFERENCES}

[1] Oni, S. T. (2004), Flexural motions of uniform beam under the actions of concentrated mass travelling with variable velocity. Journal of Nigerian Association of Mathematical Physics, 8, 215-224.

[2] Timoshenko, S. (1921), On the correction for shear of the differential equation for transverse vibration of prismatic bars. Phil. Mag. Ser 6, 5, 4-74.

[3] Ogunbamike, O. K. (2021), Dynamic response of uniform cantilever beams on elastic foundation. African Journal of Mathematics and Statistics Studies, 4(1): 47-62.

[4] Stanisic, M. M. (1968), On response of plate to a multi-masses moving system. Acta Mechanical 5, 37-53.

[5] Sadiku, S. and Leipholz, H. H. E. (1989), On the dynamics of elastic system with moving concentrated masses. Ingenieur, Archiv, 57, 223-242.

[6] Ogunbamike, O. K. (2021), Damping effects on the transverse motions of axially loaded beams carrying uniform distributed load. Applications of Modelling and Simulation 5, pp. 88-101,

[7] Esmailzadeh, E. and Ghorashi, M. (1995), Vibration analysis of beams traversed by uniform partially distributed masses. Journal of Sound and Vibration, 184, 9-17.

[8] Timoshenko, S. P. (1992), On the forced vibration of bridges. Philosophy Magazine, ser 6(43), 1018.

[9] Gbadeyan, J. A. and Oni, S. T. (1992), Dynamic response to moving concentrated masses of elastic plates on a non-Winkler elastic foundation. Journal of Sound and Vibration, 154, 343-358.

[10] Milomir, M., Stanisic, M. M., and Hardin, J. C. (1969), On the response of beam to an arbitrary number of concentrated moving masses. Journal of Franklin Institute, 287, no. 2.

[11] Stanisic, M. M., Euler, J. A., and Montomery, S. T. (1974), On a theory concerning the dynamical behavior of structures carrying moving masses. Ingenieur Archiv, 43,295305.

[12] Inglis, C. E. (1934), A mathematical treatise on vibrations in railway bridges. Cambridge University Press.

[13] Muscolino, G. and Palmeri, A. (2007), Response of beams resting on viscoelastically damped foundation to moving oscillators. International Journal of Solids and Structures, 44(5),. 1317-1336.

[14] Steele, C .R. (1971), Beams and shells with moving loads. International Journal of solid and structures, 7, 1171- 1198.

[15] Wu, J. S. and Dai, C. W. (1987), Dynamic response of multi-span non-uniform beams due to moving loads. Journal of Structural Engineering, 115, 459-474.. 
[16] Dugush, Y. A. and Eisenberger, M. (2002), Vibration of non-uniform continuous beams under moving loads. Journal of Sound and vibration,. 911-927.

[17] Ahmadian, M., Esmailzadeh, E., and Asgari, M. (2006), Dynamic analysis of nonuniform cross sections beam under moving mass using finite element method. Proceeding of $4^{\text {th }}$ CSME Forum, Clgari, Alberta, Canada, 115, May $21^{\text {st }}-23^{\text {rd }}, 459$ 474.

[18] Oni, S. T. (1991), On the dynamic response of elastic structure to moving multi-mass system. Ph.D. Thesis, University of Ilorin, Ilorin Nigeria.

[19] Oni, S. T. and Awodola, T.O. (2003), Vibrations under a moving load of a non-uniform Rayleigh beam on variable elastic foundation. Journal of the Nigerian Association of Mathematics Physics, 7, 191-206.

[20] Oni, S. T. and Awodola, T. O (2010), Dynamic response under a moving load of an elastically supported non-prismatic Bernoulli-Euler beam on variable elastic foundation. Latin American Journal of Solids and Structures, 7, 3-20.

[21] Struble, R. (1962), Nonlinear differential equation. New York, San-Francisco, Toronto, London, Sydney.

[22] Junkins, J. L. and Kim, Y. (1993): Introduction to dynamics and control of Flexible Structure

American Institute of Aeronautic and Astronautic, Inc. Washington, DC.

[23] Wu, J. J. (2005), Vibration analysis of a portal frame under the action of moving distributed masses using moving mass element. International Journal of Numerical Methods in Engineering, 62, 2028-2052.

[24] Irvine, T. (2010), Transverse vibration of a beam via the Finite Element Method, Revision F, Vibration data.. 